ORIGINAL ARTICLE

\title{
Risk factors for incident neck and shoulder pain in hospital nurses
}

\author{
J Smedley, H Inskip, F Trevelyan, P Buckle, C Cooper, D Coggon
}

Occup Environ Med 2003;60:864-869

See end of article for authors' affiliations

.....................

Correspondence to:

Dr J Smedley, MRC

Environmental

Epidemiology Unit,

Southampton General

Hospital, Southampton

SO16 6YD, UK

jcs@mrc.soton.ac.uk

Accepted

23 December 2002
Aim: To assess the incidence and risk factors for neck and shoulder pain in nurses.

Methods: A longitudinal study of neck and shoulder pain was carried out in female nurses at two hospitals in England. Personal and occupational risk factors were assessed at baseline. The self reported incidence of symptoms in the neck and shoulder region was ascertained at three-monthly intervals over two years. A Cox regression model was used to estimate hazard ratios (HRs) for incident neck/shoulder pain during follow up in nurses who had been pain free for at least one month at baseline.

Results: The baseline response rate was $56 \%$. Of 903 women who were pain free at baseline, 587 (65\%) completed at least one follow up while still in the same job. During an average of 13 months, $34 \%$ of these (202 women) reported at least one episode of neck/shoulder pain. The strongest predictor of pain in the neck/shoulder was previous history of the symptom (HRs up to 3.3). For physical exposures at work, the highest risks (HRs up to 1.7) were associated with specific patient handling tasks that involved reaching, pushing, and pulling. Nurses who reported low mood or stress at baseline were more likely to develop neck/shoulder pain later (HR 1.5). Workplace psychosocial factors (including job demands, satisfaction, and control) were not associated with incident neck/shoulder symptoms.

Conclusions: Neck/shoulder pain is common among hospital nurses, and patient handling tasks that involve reaching and pulling are the most important target for risk reduction strategies.
$\mathrm{H}$ ospital nurses have a high prevalence of low back pain, ${ }^{1-4}$ and the risk of low back disorders from physical activities in patient care has been the focus of extensive research. ${ }^{1-12}$ In comparison, relatively few studies have explored the influence of patient handling on neck and shoulder pain, ${ }^{8-10}{ }^{12-14}$ and most of these have been cross sectional in design. ${ }^{10}$ 12-14

As part of a prospective investigation to assess the impact of an ergonomic intervention on musculoskeletal symptoms, we collected longitudinal data on the occurrence of neck and shoulder pain in a cohort of nurses. We here present an analysis of the risk of incident neck/shoulder pain in relation to personal and occupational risk factors ascertained at baseline.

\section{METHODS}

The study was carried out at two similar acute hospitals in the south of England, both of which provided in-patient care across a range of clinical specialties other than mental health. From personnel records, we identified all nurses employed by these hospitals, excluding agency staff, student nurses, and those who worked in community roles. Each nurse was sent a baseline postal questionnaire, followed if necessary by a reminder after six weeks. Among other things, the questionnaire asked about the following: age; sex; height; weight; details of current occupation; frequency of exposure to various common nursing activities (with and without assistance from colleagues or mechanical aids); perceived psychosocial aspects of work, including job demand and satisfaction; experience of non-musculoskeletal symptoms including low mood and stress; and history of pain in the neck and/or shoulders. Questions about psychosocial stressors in the workplace were taken from the Whitehall II study, ${ }^{15}$ and were used to derive a score in relation to each of five aspects of work: demand, interest, control, support, and satisfaction. For analysis, these scores were partitioned into thirds (low, intermediate, and high). Questions about workplace activities and experience of non-musculoskeletal symptoms were based on a questionnaire that had been used previously to study occupational risk factors for low back pain in hospital nurses. ${ }^{5} \mathrm{Neck} /$ shoulder pain was defined as pain lasting for longer than a day in an anatomical distribution bounded by the occiput and the lower edges of the scapulae that was illustrated with a diagram (fig 1). It was ascertained through a question derived from the Nordic Musculoskeletal Questionnaire. ${ }^{16}$

Subjects who responded to the baseline questionnaire were asked whether they would take part in a subsequent longitudinal phase of data collection, and those who agreed were sent shorter follow up questionnaires at three-monthly intervals over the next two years. The follow up questionnaire included sections about new neck/shoulder pain since the previous contact and about any changes in occupation. Nurses who did not respond to a follow up questionnaire were sent a reminder and were included in the next follow up. Those who failed to respond to two consecutive threemonthly questionnaires were dropped from further follow up.

The main analysis presented in this paper was restricted to female nurses who had been free from pain in the neck or shoulder for at least one month at baseline, and who completed at least one follow up questionnaire while still in the same job as when they entered the study. Cox regression was used to calculate the risk of incident neck/shoulder pain during follow up according to both occupational and nonoccupational factors measured at baseline. Risk estimates were summarised as hazard ratios (HRs) with 95\% confidence intervals (CIs). Where a nurse changed her job during the longitudinal phase of the study, follow up was censored after the last questionnaire that preceded the change.

Abbreviations: $\mathrm{Cl}$, confidence interval; $\mathrm{HR}$, hazard ratio 


\section{Main messages}

- Neck/shoulder pain is less common than low back pain in nurses, but is nevertheless an important cause of morbidity and sickness absence.

- Of the occupational risk factors studied, physical activities were more strongly associated with neck/ shoulder pain than psychosocial variables. Physical tasks that required pulling or pushing with the outstretched arm/shoulder carried the highest risk of neck and shoulder symptoms.

- Previous history of neck/shoulder pain is a stronger predictor of future symptoms than any occupational exposure.

Although the investigation was conceived as an intervention study, the intervention (which included the introduction of new equipment and training at one of the two hospitals) did not begin until 18 months after the start of follow up. Moreover, when nurses' patterns of work were reassessed 14 months later, there appeared to have been little change at either hospital. ${ }^{16 a}$ Therefore, when analysing risk factors for incident neck pain, we did not try to take account of changes in activities over the course of follow up in nurses who remained in the same job.

\section{RESULTS}

The study population comprised 2200 nurses. The baseline survey was returned by 1239 subjects (56\% of those mailed)

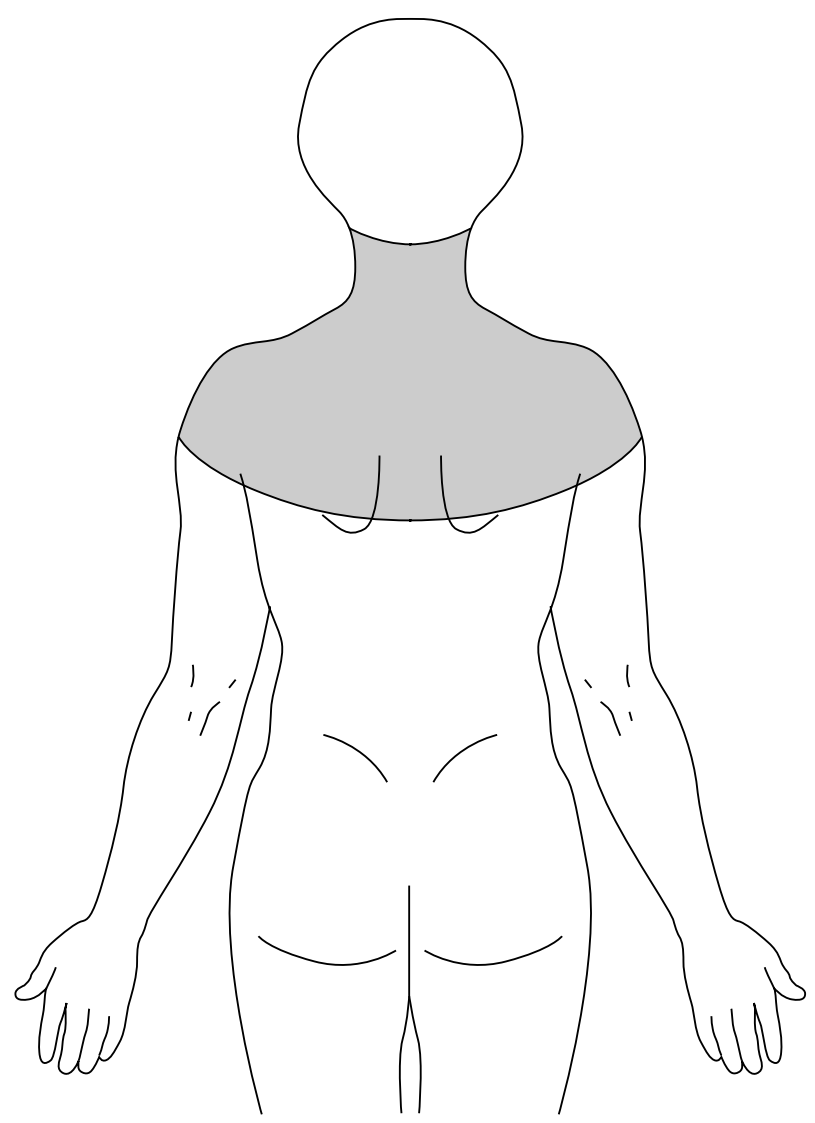

Pain lasting for longer than a day

\section{Policy implications}

- Handling equipment designed to reduce the risk of back pain (particularly slide sheets) might increase nurses' exposure to pulling and reaching. More research is needed to explore this further. Meanwhile, ergonomic interventions in hospitals should include consideration of the risk of symptoms in the neck and shoulder as well as low back pain.

- Job changes or redeployment might be considered for nurses with a recent or prolonged previous history of neck/shoulder pain or low back pain, but only if the risk remains high after optimal management of physical exposures at work.

who had an age and sex distribution similar to that of the study population as a whole. An initial descriptive analysis ${ }^{17}$ confirmed that nurses in the two hospitals were similar in age, and exposure to physical and psychosocial factors at work.

Nineteen responders were excluded from further analysis because they reported working in midwifery or non-nursing jobs. Of those who remained, 1157 were women. The age of these women ranged from 19 to 67 years with a mean age of 39 years. Approximately half worked full time, 19\% were healthcare assistants, and $76 \%$ were qualified nurses of staff nurse level (D grade) or higher. Forty nine per cent reported that they had suffered from neck/shoulder pain at some time in their life, $35 \%$ in the past year, and $22 \%$ in the past month. Twenty seven per cent had taken time off work because of neck/shoulder pain at some stage in their careers.

Nine hundred and three nurses indicated that they had not experienced pain in the neck or shoulder during the month before answering the baseline questionnaire. Among these, 613 women $(68 \%)$ answered at least one three-monthly questionnaire, but 26 of these had changed their job before the first follow up. Our analysis of incident symptoms focused on the remaining 587 women. Table 1 summarises the extent of follow up among these 587, of whom 190 stayed under follow up until the end of the study. The remaining nurses were censored from analysis if they changed job ( $n=68$ ) if they developed neck/shoulder pain, or if they failed to return two successive questionnaires.

Among the 587 female nurses in the longitudinal analysis, $202(34 \%)$ reported at least one episode of pain in the neck or shoulder during an average follow up period of 13 months. Table 2 shows the risk of incident neck/shoulder pain by age,

Table 1 Extent of follow up among female nurses who were free from neck/shoulder pain at baseline

\begin{tabular}{lllll}
\hline Number of & $\begin{array}{l}\text { Number } \\
\text { reporting } \\
\text { nurses still } \\
\text { nollow up } \\
\text { under follow } \\
\text { time point }\end{array}$ & $\begin{array}{l}\text { pain for the } \\
\text { up }\end{array}$ & $\begin{array}{l}\text { Number } \\
\text { fensored time } \\
\text { to job change }\end{array}$ & $\begin{array}{l}\text { Number lost } \\
\text { to follow up }\end{array}$ \\
\hline 1 & 587 & 81 & 9 & 45 \\
2 & 452 & 43 & 3 & 47 \\
3 & 359 & 26 & 7 & 20 \\
4 & 306 & 18 & 4 & 19 \\
5 & 265 & 11 & 7 & 10 \\
6 & 237 & 9 & 4 & 8 \\
7 & 216 & 10 & 4 & 12 \\
8 & 190 & 4 & - & 186 \\
\hline
\end{tabular}

Figure 1 Definition of neck/shoulder pain. 
height, and body mass index. There was no indication that risk varied importantly with height. Weak associations with increasing age and body mass index were not statistically significant.

At baseline, 208 nurses from the longitudinal analysis had reported that they frequently felt tired, low, tense, or under stress. After adjustment for age and BMI, the risk of incident neck/shoulder pain was significantly increased in these women (HR 1.5, 95\% CI 1.2 to 2.1). All subsequent analyses were adjusted for the occurrence of these psychological symptoms as well as for age and BMI.

Although all of the women included in the longitudinal analysis were free from neck and shoulder pain at baseline, some of them had experienced musculoskeletal symptoms previously. Table 3 presents the risk of incident neck/shoulder pain during follow up according to past history of musculoskeletal pain at baseline. Incidence increased with longer total duration of previous neck/shoulder pain and with decreasing interval since the last episode. The risk of new neck/shoulder pain was particularly high among nurses who reported previous neck/shoulder pain that had lasted for longer than four weeks in total and that had last occurred within the year before answering the baseline questionnaire (HR 3.3, 95\% CI 1.9 to 5.8). A similar pattern of increased incident neck/shoulder pain was seen in nurses who reported a past history of low back pain at baseline. Although the risk estimates were somewhat lower than for previous history of neck/shoulder symptoms, low back pain was more common among this population of nurses than neck/shoulder pain (lifetime prevalence 59\% compared to 36\%). The attributable proportion in relation to lifetime experience of symptoms (HR 1.9 for low back pain and 2.1 for neck/shoulder pain) was higher for low back pain (31\%) than for neck/shoulder pain $(20 \%)$.

Table 4 shows the risk of incident neck/shoulder pain according to psychosocial aspects of work assessed at baseline. Hazard ratios were generally close to unity, and no clear trends were apparent with respect to reported job demands, interest, control, support at work, or job satisfaction.

Table 5 presents the risk of incident neck/shoulder pain in relation to patient handling tasks carried out without the assistance of nursing colleagues or mechanical aids. There was a clear increase of risk in nurses who frequently assisted patients to mobilise using a walking stick, Zimmer frame, or crutches (HR for highest versus lowest frequency 1.6, 95\% CI 1.1 to 2.3 ); moved patients in a wheelchair, bed, hoist, trolley,

Table 2 Risk of incident neck/shoulder pain according to age, height, and body mass index (BMI)

\begin{tabular}{|c|c|c|c|}
\hline Risk factor & $\begin{array}{l}\text { Number of } \\
\text { nurses* }\end{array}$ & $\begin{array}{l}\text { Cases of neck/ } \\
\text { shoulder pain } \\
\text { Number (\%) }\end{array}$ & $\begin{array}{l}\text { Hazard ratio } \\
(95 \% \mathrm{Cl})\end{array}$ \\
\hline \multicolumn{4}{|c|}{ Age at baseline (years) } \\
\hline$<30$ & 105 & 31 (30) & 1 \\
\hline $30-39$ & 221 & 74 (33) & $1.1(0.7$ to 1.6$)$ \\
\hline $40-49$ & 153 & $55(36)$ & $1.2(0.8$ to 1.8$)$ \\
\hline \multirow[t]{2}{*}{$\geqslant 50$} & 103 & $42(41)$ & $1.4(0.9$ to 2.3$)$ \\
\hline & & & $p_{\text {trend }}=0.1$ \\
\hline \multicolumn{4}{|l|}{ Height $(\mathrm{cm})$} \\
\hline$<160$ & 139 & $50(36)$ & 1 \\
\hline $160-164.9$ & 157 & $56(36)$ & $1.0(0.7$ to 1.4$)$ \\
\hline $165-169.9$ & 164 & 53 (32) & $0.8(0.6$ to 1.2$)$ \\
\hline$\geqslant 170$ & 124 & $43(35)$ & $0.9(0.6$ to 1.3$)$ \\
\hline \multicolumn{4}{|l|}{$\mathrm{BMI}\left(\mathrm{kg} / \mathrm{m}^{2}\right)$} \\
\hline$<25$ & 352 & $119(34)$ & 1 \\
\hline $25-29.9$ & 152 & $54(36)$ & $1.1(0.8$ to 1.5$)$ \\
\hline \multirow[t]{2}{*}{$\geqslant 30$} & 66 & $26(39)$ & $1.3(0.9$ to 2.1$)$ \\
\hline & & & $P_{\text {trend }}=0.2$ \\
\hline
\end{tabular}

Table 3 Risk of incident neck/shoulder pain according to previous history of musculoskeletal pain at baseline

\begin{tabular}{|c|c|c|c|}
\hline $\begin{array}{l}\text { Previous } \\
\text { musculoskeletal pain }\end{array}$ & $\begin{array}{l}\text { Number } \\
\text { of nurses }\end{array}$ & $\begin{array}{l}\text { Cases of } \\
\text { neck/ } \\
\text { shoulder } \\
\text { pain during } \\
\text { follow up } \\
\text { Number (\%) }\end{array}$ & $\begin{array}{l}\text { Hazard ratio } \\
(95 \% \mathrm{CI})\end{array}$ \\
\hline \multicolumn{4}{|l|}{$\begin{array}{l}\text { Neck/shoulder pain } \\
\text { Interval since last neck pain }\end{array}$} \\
\hline Never & 355 & $99(28)$ & 1 \\
\hline$>1$ year ago at baseline 1 & 101 & $42(42)$ & $1.6(1.1$ to 2.3$)$ \\
\hline $\begin{array}{l}\text { Within the past year at } \\
\text { baseline }\end{array}$ & 99 & $54(55)$ & $2.8(2.0$ to 3.9$)$ \\
\hline \multicolumn{4}{|c|}{ Total duration of previous neck pain } \\
\hline Never & 355 & $99(28)$ & 1 \\
\hline$<1$ week & 80 & $31(39)$ & $1.7(1.1$ to 2.5$)$ \\
\hline $1-4$ weeks & 64 & $35(55)$ & $2.3(1.5$ to 3.3$)$ \\
\hline$>4$ weeks & 55 & $29(53)$ & $2.6(1.7$ to 4.0$)$ \\
\hline $\begin{array}{l}>4 \text { weeks and pain within } \\
\text { past year (compared to } \\
\text { never had pain) }\end{array}$ & 29 & $16(55)$ & $\begin{array}{l}\mathrm{p}_{\text {trend }}<0.001 \\
3.3(1.9 \text { to } 5.8)\end{array}$ \\
\hline \multirow{2}{*}{\multicolumn{4}{|c|}{$\begin{array}{l}\text { Low back pain } \\
\text { Interval since last back pain }\end{array}$}} \\
\hline & & & \\
\hline$>1$ year ago at baseline 1 & 111 & $46(41)$ & 1.8 (1.2 to 2.7$)$ \\
\hline $\begin{array}{l}\text { Within the past year at } \\
\text { baseline }\end{array}$ & 221 & $95(43)$ & $1.9(1.4$ to 2.7$)$ \\
\hline \multirow{2}{*}{\multicolumn{4}{|c|}{ Total duration of previous back pain }} \\
\hline & & & \\
\hline$<1$ week & 76 & $25(33)$ & $1.4(0.9$ to 2.3$)$ \\
\hline $1-4$ weeks & 109 & $46(42)$ & 1.8 (1.2 to 2.7$)$ \\
\hline$>4$ weeks & 144 & $70(49)$ & 2.3 (1.6 to 3.3 ) \\
\hline $\begin{array}{l}>4 \text { weeks and pain within } 1 \\
\text { past year (compared to } \\
\text { never had pain) }\end{array}$ & 107 & $55(51)$ & $\begin{array}{l}p_{\text {trend }}<0.001 \\
2.6(1.8 \text { to } 3.9)\end{array}$ \\
\hline
\end{tabular}

*Data were missing for up to 36 nurses.

†Adjusted for age, BMI, and frequently feeling tired, low, tense, or under stress.

Table 4 Risk of incident neck/shoulder pain according to psychosocial factors at work

\begin{tabular}{|c|c|c|c|}
\hline & $\begin{array}{l}\text { Number of } \\
\text { nurses }\end{array}$ & $\begin{array}{l}\text { Cases of neck/ } \\
\text { shoulder pain } \\
\text { Number (\%) }\end{array}$ & $\begin{array}{l}\text { Hazard ratio } \\
(95 \% \mathrm{CI})\end{array}$ \\
\hline \multicolumn{4}{|l|}{ Demand } \\
\hline Low & 155 & $53(34)$ & 1 \\
\hline Intermediate & 216 & $77(36)$ & $1.0(0.7$ to 1.4 \\
\hline High & 177 & $62(35)$ & $0.9(0.7$ to 1.4 \\
\hline \multicolumn{4}{|l|}{ Interest } \\
\hline High & 203 & $67(33)$ & 1 \\
\hline Intermediate & 186 & $63(34)$ & $1.1(0.8$ to 1.5 \\
\hline Low & 160 & $62(39)$ & $1.2(0.9$ to 1.8 \\
\hline \multicolumn{4}{|l|}{ Control } \\
\hline Low & 190 & 70 (37) & 1 \\
\hline Intermediate & 200 & $63(32)$ & 0.9 (0.6 to 1.3 \\
\hline High & 157 & $58(37)$ & 1.1 ( 0.8 to 1.6 \\
\hline \multicolumn{4}{|l|}{ Support } \\
\hline High & 182 & $67(37)$ & 1 \\
\hline Intermediate & 202 & $67(33)$ & 0.9 (0.6 to 1.2 \\
\hline Low & 125 & $46(37)$ & 0.9 (0.6 to 1.3 \\
\hline \multicolumn{4}{|l|}{ Satisfaction } \\
\hline Low & 160 & $49(31)$ & 1 \\
\hline Intermediate & 224 & $86(38)$ & 1.3 (0.9 to 1.8 \\
\hline High & 150 & 50 (33) & 1.2 (0.8 to 1.8 \\
\hline
\end{tabular}

*Data were missing for up to 41 nurses.

†Adjusted for age, BMI, and frequently feeling tired, low, tense, or under stress. 
Table 5 Risk of incident neck/shoulder pain according to frequency of unaided patient handling activities

\begin{tabular}{|c|c|c|c|c|}
\hline Work activity* & $\begin{array}{l}\text { Frequency } \\
\text { per shift }\end{array}$ & $\begin{array}{l}\text { Number of } \\
\text { nursest }\end{array}$ & $\begin{array}{l}\text { Cases of neck/shoulder } \\
\text { pain during follow up } \\
\text { Number (\%) }\end{array}$ & $\begin{array}{l}\text { Hazard ratio } \\
(95 \% \mathrm{Cl}) \ddagger\end{array}$ \\
\hline \multirow{3}{*}{$\begin{array}{l}\text { Assist patient to move from lying to } \\
\text { sitting or from sitting to lying }\end{array}$} & 0 & 171 & $50(29)$ & 1 \\
\hline & $1-4$ & 214 & 80 (37) & $1.3(0.9$ to 1.8$)$ \\
\hline & & 112 & $43(38)$ & $1.4(0.9$ to 2.1$)$ \\
\hline \multirow{2}{*}{$\begin{array}{l}\text { Reposition a patient who has slumped } \\
\text { sin a chair }\end{array}$} & 0 & 347 & $115(33)$ & 1 \\
\hline & $\geqslant 1$ & 144 & $57(40)$ & 1.3 (0.9 to 1.8 ) \\
\hline \multirow{3}{*}{$\begin{array}{l}\text { Assist a patient to mobilise using a } \\
\text { walking stick, Zimmer frame, or crutches }\end{array}$} & 0 & 217 & $65(30)$ & 1 \\
\hline & $1-4$ & 197 & 75 (38) & 1.4 (1.0 to 1.9 ) \\
\hline & $\geqslant 5$ & 113 & $47(42)$ & $1.6(1.1$ to 2.3$) \S$ \\
\hline \multirow{3}{*}{$\begin{array}{l}\text { Move a patient around in a wheelchair, } \\
\text { bed, hoist, trolley, commode, etc }\end{array}$} & 0 & 158 & $48(30)$ & 1 \\
\hline & $1-4$ & 229 & 78 (34) & $1.2(0.8$ to 1.7$)$ \\
\hline & $\geqslant 5$ & 122 & $54(44)$ & $1.6(1.1$ to 2.4$) \S$ \\
\hline \multirow{3}{*}{$\begin{array}{l}\text { Assist a patient to sit up from a lying } \\
\text { position }\end{array}$} & 0 & 177 & 55 (31) & 1 \\
\hline & $1-4$ & 203 & $73(36)$ & $1.2(0.9$ to 1.8$)$ \\
\hline & $\geqslant 5$ & 109 & $43(39)$ & $1.3(0.9$ to 1.9$)$ \\
\hline \multirow{3}{*}{$\begin{array}{l}\text { Assist a patient to move up/down the } \\
\text { bed }\end{array}$} & 0 & 241 & $85(35)$ & 1 \\
\hline & $1-4$ & 165 & $47(28)$ & $0.8(0.5$ to 1.1$)$ \\
\hline & $\geqslant 5$ & 85 & $35(41)$ & $1.1(0.8$ to 1.7$)$ \\
\hline \multirow{3}{*}{ Reposition (turn or roll) a patient } & 0 & 311 & $105(34)$ & 1 \\
\hline & $1-4$ & 135 & $43(32)$ & $1.0(0.7$ to 1.4$)$ \\
\hline & $\geqslant 5$ & 40 & $19(48)$ & $1.5(0.9$ to 2.4$)$ \\
\hline \multirow[t]{2}{*}{ Transfer a patient in/out of a bath } & 0 & 425 & $140(33)$ & 1 \\
\hline & $\geqslant 1$ & 94 & $40(43)$ & $1.4(1.0$ to 2.0$)$ \\
\hline \multirow{3}{*}{$\begin{array}{l}\text { Wash/dress a patient while they are } \\
\text { on a chair/commode }\end{array}$} & 0 & 305 & $103(34)$ & \\
\hline & $\begin{array}{l}1-4 \\
\geqslant 5\end{array}$ & $\begin{array}{r}171 \\
54\end{array}$ & $\begin{array}{l}60(35) \\
25(46)\end{array}$ & $1.1(0.8$ to 1.5$)$ \\
\hline & $\geqslant 5$ & 54 & $25(46)$ & $1.7(1.1$ to 2.8$) \S$ \\
\hline \multirow{5}{*}{$\begin{array}{l}\text { Wash/dress a patient while they are } \\
\text { on an ambulift/hoist } \\
\text { Wash/dress a patient while they are } \\
\text { on their bed }\end{array}$} & 0 & 479 & $167(35)$ & 1 \\
\hline & $\geqslant 1$ & 36 & $13(36)$ & $1.1(0.6$ to 1.9$)$ \\
\hline & 0 & 260 & $85(33)$ & 1 \\
\hline & $1-4$ & 194 & $66(34)$ & $1.1(0.8$ to 1.5$)$ \\
\hline & $\geqslant 5$ & 60 & $27(45)$ & $1.6(1.0$ to 2.5$)$ \\
\hline
\end{tabular}

or commode (HR for highest versus lowest frequency 1.6, $95 \%$ CI 1.1 to 2.4 ); or washed and dressed patients while they were seated on a chair or commode (HR for highest versus lowest frequency $1.7,95 \%$ CI 1.1 to 2.8 ). Several other activities were associated with smaller increases in risk that were not statistically significant. The tasks that were associated with a significantly high risk of incident neck and shoulder pain ( $\mathrm{HR} \geqslant 1.5$ and $\mathrm{p}<0.05$ for the highest frequency category) were used to calculate the attributable proportion of symptoms due to physical work. Forty two per cent of nurses who reported new neck/shoulder pain during follow up had carried out at least one of these four high risk activities (assist a patient to mobilise using a walking stick, Zimmer frame, or crutches; move a patient around in a wheelchair, bed, hoist, trolley, commode, etc; wash/dress a patient while they are on a chair or commode and wash/dress a patient while they are on their bed). The attributable proportion for carrying out one or more of these activities more than five times per shift (versus not carrying out any of them more than five times per shift) was $22 \%$.

Table 6 shows the risk of incident neck/shoulder pain according to the number of different unaided patient handling tasks carried out in an average working shift. In this analysis, attention was restricted to the eight activities from table 5 that showed the strongest associations with symptoms when examined separately. Risk tended to increase with the number of tasks performed, although the trend was not statistically significant.

\section{DISCUSSION}

In this longitudinal study, the strongest predictor of incident neck/shoulder pain was previous history of the symptom.
Incidence also appeared to be influenced importantly by psychological morbidity (low mood and feeling stressed) and by a number of patient handling tasks commonly carried out by nurses, although the latter differed from those that have been associated with low back pain. In contrast to physical activities, workplace psychosocial factors had little impact on risk.

Table 6 Risk of incident neck/shoulder pain according to number of different unaided patient handling activities performed in an average shift

\begin{tabular}{|c|c|c|c|}
\hline $\begin{array}{l}\text { Number of activities } \\
\text { performed unaided* }\end{array}$ & $\begin{array}{l}\text { Number of } \\
\text { nurses }\end{array}$ & $\begin{array}{l}\text { Cases of neck/ } \\
\text { shoulder pain } \\
\text { during follow up } \\
\text { Number (\%) }\end{array}$ & $\begin{array}{l}\text { Hazard ratio } \\
(95 \% \mathrm{Cl})\end{array}$ \\
\hline $\begin{array}{l}0 \\
1-2 \\
3-4 \\
5-6 \\
7 \\
8\end{array}$ & $\begin{array}{r}43 \\
57 \\
82 \\
98 \\
113 \\
93\end{array}$ & $\begin{array}{l}15(35) \\
17(30) \\
21(26) \\
31(32) \\
41(36) \\
36(39)\end{array}$ & $\begin{array}{l}1 \\
1.1(0.6 \text { to } 2.2) \\
0.8(0.4 \text { to } 1.6) \\
1.1(0.6 \text { to } 2.0) \\
1.3(0.7 \text { to } 2.3) \\
1.5(0.8 \text { to } 2.8) \\
\text { Prrend }=0.09\end{array}$ \\
\hline
\end{tabular}

${ }^{*}$ The activities considered were: (a) assisting a patient to move from lying to sitting or sitting to lying; (b) assisting a patient to mobilise using a walking stick, Zimmer frame, or crutches; (c) moving a patient around on a wheelchair, bed, hoist, trolley, commode, etc; (d) assisting a patient to sit up from a lying position; (e) repositioning (turning or rolling) a patient; (f) transferring a patient in/out of a bath; (g) washing/dressing a patient while they are on a chair/commode; and (h) washing/dressing a patient while they are on a bed.

†Adjusted for age, BMI, and frequently feeling tired, low, tense, or under stress. 
The investigation was designed to assess the impact of ergonomic improvements and training on musculoskeletal symptoms and disability by comparing the two participating hospitals before and after one of them implemented a planned intervention. However, because of practical difficulties, the intervention did not begin until 18 months after the start of data collection. Moreover, its impact on patient handling, at least over the next 14 months, was only slight. ${ }^{16 a}$ Therefore, we think it unlikely that major changes occurred in the occupational activities of our cohort of nurses over the course of follow up. Nor was there any important reorganisation of services at either hospital during the course of the study.

The scope for change in occupational activities was probably greatest where a nurse moved to a new job, and for this reason, we censored follow up before job transfers. It is possible that some participants moved from heavy work to positions that were physically less demanding because they were having problems with their neck. If so, the risks associated with patient handling activities could have been underestimated. However, in our experience, it would be unusual for such transfers to occur within three months of the onset of a new symptom episode.

Bias could also have arisen from the incomplete response to questionnaires. In particular, completion of the initial questionnaire may have been selectively higher in nurses with a history of neck trouble, in which case baseline estimates of prevalence will have been inflated. However, this would not affect associations with new episodes of pain during follow up.

One further methodological concern is the possibility that performance of certain physical activities made some nurses more aware of neck symptoms, and therefore more likely to report them. In the absence of objective diagnostic criteria, this problem is unavoidable. However, if the long term goal is to prevent distress and disability, factors that influence the awareness of symptoms are potential targets for intervention, and should not be regarded simply as a source of bias.

The one year and one month prevalences of neck/shoulder pain that we recorded at baseline (35\% and 22\%) were somewhat lower than those found in previous cross sectional surveys of nurses, ${ }^{918} 19$ possibly because of differences in case definition. Nevertheless, the symptom was common, and had been a frequent cause of sickness absence ( $27 \%$ of subjects). This accords with the observation that in an Italian general hospital, $15 \%$ of sick leave among nurses was attributed to pain in the upper back and neck. ${ }^{20}$

Neck/shoulder pain was more likely to develop during follow up in nurses who at baseline reported being frequently tired, low, tense, or under stress. An association of neck and shoulder pain with depression, anxiety, and poor perceived health has been noted in several previous longitudinal investigations, ${ }^{8} 2122$ although not in all. ${ }^{23}$ Importantly, these psychological symptoms were present at a time when subjects were free from neck/shoulder pain, which suggests that they did not occur as a consequence of underlying musculoskeletal disease. A more plausible explanation for the association is that anxiety and depression modify the central processing of sensory information, and so increase the distress caused by painful stimuli.

Our finding that previous neck/shoulder pain strongly predicts further occurrence of the symptom is consistent with other studies, ${ }^{21}{ }^{24}$ and indicates that like low back complaints, ${ }^{5}$ neck and shoulder disorders have a marked tendency to recur. Previous low back pain also predicted new episodes of neck/shoulder pain. Moreover, because of the higher lifetime prevalence of low back pain, the attributable proportion of new neck/shoulder pain was higher for previous symptoms in the low back than in the neck/ shoulder region. It appears that the risk of recurrent neck/ shoulder pain is highest where previous musculoskeletal symptoms have been prolonged and have been present in the past 12 months. This is of practical relevance to pre-employment screening and also to the rehabilitation of workers after episodes of illness. Exclusion from a job could only be justified if the absolute risk of future illness was high and could not be satisfactorily reduced by modifications to the working environment and methods.

We found little evidence that psychosocial aspects of work influenced the development of neck/shoulder pain. An association with factors such as low support, high demands, and low decision latitude has been observed in several earlier studies of nurses. ${ }^{12} 13192526$ Moreover, an interaction between physical and psychosocial factors at work has been suggested in relation to musculoskeletal symptoms in the upper limb. ${ }^{27}$ Most of these investigations have been cross sectional, and the temporal relation between the workplace factors and symptoms is not clear.9 ${ }^{13} 162526$ However, the relation with psychosocial factors has also been found in longitudinal studies in nurses. ${ }^{8}{ }^{28}$ The absence of stronger associations in our study could reflect differences in the heterogeneity and severity of psychosocial stressors to which our cohort of nurses was exposed.

In comparison with psychosocial variables, we found that physical activities in the workplace were stronger predictors of incident neck/shoulder pain. Other investigators have reported an increased risk or severity of neck pain in relation to heavy lifting and uncomfortable posture, ${ }^{26}$ physical stress at work, ${ }^{29}$ working with the hands above shoulder height, ${ }^{24}$ 30-32 shoulder elevation, and neck flexion. ${ }^{33-35}$ However, no previous studies have examined the incidence of neck pain in relation to specific nursing tasks. The risk of incident neck/shoulder pain increased modestly with increasing number of physical tasks, but a relatively high risk was associated with a very high number of tasks $(>8)$. This is likely to reflect the fact that nurses caring for very dependent patients are frequently exposed to a variety of high risk activities and that these nurses are at particularly high risk.

We found that neck pain was associated particularly with helping patients to mobilise using a walking aid, moving patients around on a chair or commode, and washing patients when positioned in a chair. These tasks, which tend to involve reaching, pushing or pulling, differ from those that we have found previously to carry an increased risk of low back pain (mainly activities that entail lifting and loading of the spine such as manual bed to chair transfers and repositioning a patient on the bed). ${ }^{5}$ The calculated attributable proportion suggests that up to $22 \%$ of nurses' neck and shoulder pain might be prevented by controlling exposure to pushing and pulling at work.

Our findings are in keeping with recent evidence that pushing and pulling is associated with a much higher risk of shoulder than low back complaints, ${ }^{36}$ and with a small laboratory based study, which showed that the use of each of three different types of sliding aids (including a draw sheet and two different friction reducing devices) to move a volunteer "patient" up in bed was associated with a similar or higher perceived exertion to nurses' shoulder regions than to their lower backs. ${ }^{37}$ This is of concern because it suggests that some of the equipment designed to reduce the risk of low back pain (for example, slide sheets) might lead to an increase in risk of neck and shoulder problems. We attempted to explore this further by comparing risk estimates for tasks carried out with sliding and handling devices and for the same tasks carried out manually or using hoists. However, this proved impossible because of the substantial overlap in exposure to patient handling with and without sliding aids and hoists. 
Although there is now a substantial body of evidence linking musculoskeletal disease with patient handling tasks carried out by nurses, the effectiveness of control measures such as mechanical aids on musculoskeletal morbidity is still uncertain. In evaluating preventive strategies, it will be important to consider effects on neck and shoulder pain as well as on low back pain. Interventions that reduce low back pain may not be good for the neck, and could even be detrimental.

\section{ACKNOWLEDGEMENTS}

We are grateful to the nurses who took part in this study, and to Vanessa Cox who provided computing support. This study was funded by the South and West Regional Health Authority and by Southampton University Hospitals NHS Trust Research and Development Directorate.

\section{Authors' affiliations}

J Smedley, H Inskip, C Cooper, D Coggon, MRC Environmental Epidemiology Unit, Community Clinical Sciences, University of Southampton, UK

F Trevelyan, P Buckle, Robens Centre for Health Ergonomics, European Institute of Health and Medical Sciences, University of Surrey, UK

\section{REFERENCES}

1 Videman T, Nurminen T, Tola S, et al. Low-back pain in nurses and some loading factors of work. Spine 1984;9:400-3.

2 Buckle PW. Epidemiological aspects of back pain within the nursing profession. Int J Nurs Stud 1987;24:319-24.

3 Abenhaim L, Suissa S, Rossignol M. Risk of recurrence of occupational back pain over three year follow up. Br J Ind Med 1988;45:829-33.

4 Smedley J, Egger P, Cooper C, et al. Manual handling activities and risk of low back pain in nurses. Occup Environ Med 1995;52:160-3.

5 Smedley J, Egger P, Cooper C, et al. Prospective cohort study of predictors of incident low back pain in nurses. BMJ 1997;314:1225-8.

6 Skovron ML, Mulvihill MN, Sterling RC, et al. Work organization and low back pain in nursing personnel. Ergonomics 1987;30:359-66

7 Klaber Moffett JA, Hughes GI, Griffiths P. A longitudinal study of low back pain in student nurses. Int J Nurs Stud 1993;30:197-212.

8 Niedhammer I, Lert F, Marne MJ. Back pain and associated factors in French nurses. Int Arch Occup Environ Health 1994;66:349-57.

9 Josephson M, Lagerström M, Hagberg M, et al. Musculoskeletal symptoms and job strain among nursing personnel: a study over a three year period. Occup Environ Med 1997; 54:681-5.

10 Estryn-Behar M, Kaminski M, Peigne E, et al. Strenuous working conditions and musculo-skeletal disorders among female hospital workers. Int Arch Occup Environ Health 1990:62:47-57.

11 Garg A, Owen BD, Carlson B. An ergonomic evaluation of nursing assistants' job in a nursing home. Ergonomics 1992;35:979-95.

12 Lagerström M, Wenemark M, Hagberg M, et al. Occupational and individual factors relating to musculoskeletal symptoms in five body regions among Swedish nursing personnel. Int Arch Occup Environ Health 1995;68:27-35.

13 Engels JA, van der Gulden JWJ, Senden TF, et al. Work related risk factors for musculoskeletal complaints in the nursing profession: results of a questionnaire survey. Occup Environ Med 1996;53:636-41.

14 Ando S, Ono Y, Shimaoka M, et al. Associations of self estimated workloads with musculoskeletal symptoms among hospital nurses. Occup Environ Med 2000;57:211-16.
15 North F, Syme SL, Feeney A, et al. Explaining socio-economic differences in sickness absence. The Whitehall II study. BMJ 1993;306:361-6.

16 Kuorinka I, Jonsson B, Kilbom A, et al. Standardised Nordic Questionnaire for the analysis of musculoskeletal symptoms. Appl Ergon 1987;18:233-7.

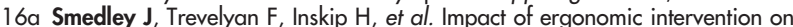
back pain in nurses. Scand J Work Environ Health 2003;29:117-23.

17 Trevelyan FC. The implementation and evaluation of an ergonomics intervention in a health care setting. Unpublished PhD thesis. Robens Centre for Health Ergonomics, European Institute for Health and Medical Sciences, University of Surrey. Int $J$ Nurs Stud.

18 Vasseljen O, Holte KA, Westgaard RH. Shoulder and neck complaints in customer relations: individual risk factors and perceived exposures at work. Ergonomics 2001;44:355-72.

19 Ahlberg-Hultén GK, Theorell T, Sigala F. Social support, job strain and musculoskeletal pain among female health care personnel. Scand J Work Environ Health 1995;21:435-9.

20 Larese F, Fiorito A. Musculoskeletal disorders in hospital nurses: a comparison between two hospitals. Ergonomics 1994;37:1205-11.

21 Croft PR, Lewis M, Papageorgiou AC, et al. Risk factors for neck pain: a longitudinal study in the general population. Pain 2001;93:317-25.

22 Leino P, Magni G. Depressive and distress symptoms as predictors of low back pain, neck-shoulder pain, and other musculoskeletal morbidity: a 10-year follow-up of metal industry employees. Pain 1993:53:89-94.

23 Estlander A-M, Takala E-P, Viikari-Juntura E. Do psychological factors predict changes in musculoskeletal pain? A prospective, two-year follow-up study of a working population. J Occup Environ Med 1998;40:445-53.

24 Viikari-Juntura E, Martikainen R, Luukkonen R, et al. Longitudinal study on work related and individual risk factors affecting radiating neck pain. Occup Environ Med 2001;58:345-52.

25 Bru E, Mykletun RJ, Svebak S. Work-related stress and musculoskeletal pain among female hospital staff. Work and Stress 1996;10:309-21.

26 Linton SJ. Risk factors for neck and back pain in a working population in Sweden. Work and Stress 1990:4:41-9.

27 Devereux JJ, Vlachonikolis IG, Buckle PW. Epidemiological study to investigate potential interaction between physical and psychosocial factors at work that may increase the risk of symptoms of musculoskeletal disorder of the neck and upper limb. Occup Environ Med 2002;59:269-77.

28 Shannon HS, Woodward CA, Cunningham CE, et al. Changes in general health and musculoskeletal outcomes in the workforce of a hospital undergoing rapid change: a longitudinal study. J Occup Health Psychol $2001 ; 6: 3-14$.

29 Mäkela $M$, Heliövaara $M$, Sievers $K$, et al. Prevalence, determinants, and consequences of chronic neck pain in Finland. Am J Epidemiol 1991;134:1356-67.

30 Holmström EB, Lindell J, Moritz U. Low back and neck/shoulder pain in construction workers: Occupational workload and psychosocial risk factors. Part 2: Relationship to neck and shoulder pain. Spine 1992;17:672-7.

31 Johansson JA. Psychosocial work factors, physical work load and associated musculoskeletal symptoms among home care workers. Scand J Psychol 1995;36:113-29.

32 Palmer KT, Walker-Bone K, Griffin MJ, et al. Prevalence and occupational associations of neck pain in the British population. Scand J Work Environ Health $2001 ; 27: 49-56$

33 Ariëns GAM, Bongers PM, Douwes $M$, et al. Are neck flexion, neck rotation, and sitting at work risk factors for neck pain? Results of a prospective cohort study. Occup Environ Med 2001;58:200-7.

34 Dartiques JF, Henry P, Puymirat E, et al. Prevalence and risk factors of recurrent cervical pain syndrome in a working population. Neuroepidemiology 1988;7:99-105.

35 Ignatius YTS, Yee TY, Yan LT. Self-reported musculoskeletal symptoms among typists and possible risk factors. J Hum Ergon 1993;22:83-93.

36 Hoozemans MJM, van der Beek AJ, Frings-Dresen MHW, et al. Pushing and pulling in association with low back and shoulder complaints. Occup Environ Med 2002;59:696-702.

37 Owen BD, Hasler-Hanson CR. A study comparing three methods for repositioning "patients" up the bed. I. Healthcare Safety, Compliance and Infection Control 1999;3:362-7. 